\title{
Mechanical circulatory supports after pulmonary thrombo- endarterectomy: why, when and how
}

\author{
Antonio Loforte ${ }^{1}$, Giuseppe Comentale ${ }^{1,2}$, Gregorio Gliozzi ${ }^{1}$, Giulio Giovanni Cavalli ${ }^{1}$, Davide Pacini ${ }^{1}$, \\ Sofia Martin-Suarez ${ }^{1}$ \\ ${ }^{1}$ Division of Cardiac Surgery, IRCCS Azienda Ospedaliero-Universitaria di Bologna, S. Orsola Hospital, Bologna, Italy; ${ }^{2}$ Division of Cardiac Surgery, \\ Department of Advanced Biomedical Sciences, University of Naples "Federico II", Naples, Italy \\ Correspondence to: Dr. Antonio Loforte, MD, PhD. Division of Cardiac Surgery, IRCCS Azienda Ospedaliero-Universitaria di Bologna, S. Orsola \\ Hospital, ALMA Mater Studiorum University of Bologna, Via Massarenti n.9, Bologna 40138, Italy. Email: antonioloforte@yahoo.it.
}

Submitted Sep 25, 2021. Accepted for publication Oct 26, 2021.

doi: 10.21037/acs-2021-pte-16

View this article at: https://dx.doi.org/10.21037/acs-2021-pte-16

Pulmonary endarterectomy (PEA) has radically changed the long-term prognosis of patients with chronic thromboembolic pulmonary hypertension (CTEPH), but the postoperative course is often demanding due to significant hemodynamic and pulmonary circulation variations (1).

A frequent complication of PEA is the 'reperfusion edema' phase, in which the lungs become unable to ensure an effective gas exchange due to temporary capillaryalveolar membrane dysfunction. It can occur in up to $20 \%$ of cases, severely worsening respiratory function (2).

The pulmonary vascular tree is a delicate circulatory system, demonstrating unique physiological features associated with gas-exchange function (3). The pulmonary vascular response to oxygen, blood flow and pressure variations is different from that of systemic circulation behavior. PEA removes the fibrotic clots which narrow the pulmonary branches and, according to the Poiseuille's law, as the pulmonary vascular surface (PVS) increases, the pulmonary arterial pressure and the right ventricle (RV) afterload decreases (4). This mechanism should hypothetically always work, however, in reality, the situation is different since the pulmonary arteries (PA) are not static pipes. They belong to a complex dynamic system which regulates itself based on the resulting received flow rates.

A similar hemodynamic model may be seen in neonates suffering from Tetralogy of Fallot (TOF), with hypoplastic pulmonary branches. In these cases, the first stage of surgery is usually the modified Blalock-Taussig shunt; a palliative technique that increases blood flow to the lungs, improving oxygenation and growth of pulmonary branches (5). Instead of larger vessels (for example, the aorta), the subclavian artery is used to shunt the systemic blood into the lungs, due to its close anatomical position to the right $\mathrm{PA}$ and the low blood pressure interface (6). In CTEPH, the pulmonary circulation is chronically under-perfused and should be 'prepared' when a normal or almost-normal blood flow is restored. The PEA procedure re-perfuses lung vessel sectors in which alveolo-capillary units have temporarily lost their original function. This results in a very dangerous circle, as the reperfusion edema-related lowering of blood oxygenation causes a reactive vasoconstriction that increases the pulmonary vascular resistances (PVR) and RV afterload. Right ventricle failure (RVF) is one of the most alarming complications that often occurs after PEA (7-10), especially in patients with advanced cardiopulmonary disease requiring mechanical circulatory support (MCS).

Pulmonary artery-left atrium oxygenators, or lungassist devices, are available for mechanical support of PEA patients (7). These pumpless devices utilize the patient's right ventricle but decrease the afterload by bypassing the pulmonary circulation. An advantage of this approach is that it's an upper configuration that allows ambulation of the patient. One disadvantage is that the cannulation itself is a more involved surgical procedure, with a median sternotomy and/or thoracotomy and therefore, is less practical in severe heart failure patients.

RV assist devices (RVADs) have been attempted in patients with RV failure due to pulmonary artery hypertension (PAH), with disappointing results (7). 
Complications, such as increased pulmonary pressures with increased flow, hemorrhage, and pulmonary edema, have been reported. Although, some of the complications may be mitigated by using lower flows with the device; extracorporeal membrane oxygenation (ECMO) remains the preferred mechanical device in CTEPH patients (8-10).

ECMO survival, after PEA, does not usually exceed $60 \%$. Veno-arterial ECMO (VA-ECMO), as it's able to provide a rapid unloading of the $\mathrm{RV}$, is the most used configuration when RVF occurs $(8,9)$. However, if RV function is normal, even a veno-venous configuration (2) could be used.

The debate about the indications/timing of ECMO after PEA still remains open, even if the literature reports that it's most widely used as a bridge to heart or lung transplantation (7-10). VA-ECMO may be implanted preoperatively to stabilize patients with decompensated RVF who are waiting for PEA, but it's most currently used in postoperative RVF in the case of difficult weaning from cardiopulmonary bypass (CPB) due to severe pulmonary hemorrhage and/or lung reperfusion edema syndrome (up to $19 \%)(8-10)$. Since weaning from MCS is not always possible, this strategy should be avoided in patients where recovery or transplantation is not achievable.

Femoro-femoral VV ECMO cannulation is usually the most chosen approach, however, an upper extremity configuration should be preferred to allow mobility during the convalescent period, especially in bridging to transplantation, where preserving mobility is crucial (9). In this scenario, VA-ECMO, at flows ranging from 2.5-4 L/min, seems the perfect choice because it not only decompresses the RV and reduces the PVRs, but it also provides good blood oxygenation that mitigates the vasoactive effects of hypoxia and the steal phenomenon related to intrapulmonary shunts $(8,10)$. In addition, the external oxygenator allows reduction of the mechanical ventilation during the 'recovery period' in order to protect the impaired alveolo-capillary units from barotrauma or high oxygen exposure.

However, timing of ECMO implantation remains the main determinant of outcomes in patients with RVF after PEA. Thus, VA-ECMO should be routinely and electively used at the time of weaning from $\mathrm{CPB}$, since it decreases $\mathrm{RV}$ afterload, ensures a pulsatile blood flow into the lung vessels, and avoids overflow episodes during the early postoperative period. Preventive VA-ECMO should be a reasonable 'bridge to recovery' strategy which mitigates the negative effects of both critical pulmonary reperfusion syndrome and severe RVF, after PEA procedures.

\section{Acknowledgments}

Funding: None.

\section{Footnote}

Conflicts of Interest: The authors have no conflicts of interest to declare.

Open Access Statement: This is an Open Access article distributed in accordance with the Creative Commons Attribution-NonCommercial-NoDerivs 4.0 International License (CC BY-NC-ND 4.0), which permits the noncommercial replication and distribution of the article with the strict proviso that no changes or edits are made and the original work is properly cited (including links to both the formal publication through the relevant DOI and the license). See: https://creativecommons.org/licenses/by-nc-nd/4.0/.

\section{References}

1. Martin-Suarez S, Gliozzi G, Loforte A, et al. Pulmonary thrombo-endarterectomy for chronic thromboembolic pulmonary artery hypertension. Curr Chall Thorac Surg 2021;3:13

2. Thistlethwaite PA, Madani MM, Kemp AD, et al. Venovenous extracorporeal life support after pulmonary endarterectomy: indications, techniques, and outcomes. Ann Thorac Surg 2006;82:2139-45.

3. Skoro-Sajer N, Marta G, Gerges C, et al. Surgical specimens, haemodynamics and long-term outcomes after pulmonary endarterectomy. Thorax 2014;69:116-22 .

4. Galiè N, Kim NH. Pulmonary microvascular disease in chronic thromboembolic pulmonary hypertension. Proc Am Thorac Soc 2006;3:571-6.

5. Baruteau AE, Belli E, Boudjemline Y, et al. Palliative Potts shunt for the treatment of children with drug-refractory pulmonary arterial hypertension: updated data from the first 24 patients. Eur J Cardiothorac Surg 2015;47:e105-10.

6. Barron DJ, Jegatheeswaran A. How and When Should Tetralogy of Fallot be Palliated Prior to Complete Repair? Semin Thorac Cardiovasc Surg Pediatr Card Surg Annu 2021;24:77-84.

7. Rosenzweig EB, Chicotka S, Bacchetta M. Right ventricular assist device use in ventricular failure due to pulmonary arterial hypertension: Lessons learned. J Heart Lung Transplant 2016;35:1272-4.

8. Nierlich P, Ristl R. Perioperative extracorporeal membrane oxygenation bridging in patients undergoing 
pulmonary endarterectomy. Interact Cardiovasc Thorac Surg 2016;22:181-7.

9. Boulate D, Mercier O, Mussot S, et al. Extracorporeal Life Support After Pulmonary Endarterectomy as a Bridge to Recovery or Transplantation: Lessons From 31
Consecutive Patients. Ann Thorac Surg 2016;102:260-8.

10. Martin-Suarez S, Gliozzi G, Fiorentino M, et al. Role and management of extracorporeal life support after surgery of chronic thromboembolic pulmonary hypertension. Ann Cardiothorac Surg 2019;8:84-92.

Cite this article as: Loforte A, Comentale G, Gliozzi G, Cavalli GG, Pacini D, Martin-Suarez S. Mechanical circulatory supports after pulmonary thrombo-endarterectomy: why, when and how. Ann Cardiothorac Surg 2022;11(2):169-171. doi: 10.21037/acs-2021-pte-16 